\title{
ROL DE LA PROTECCIÓN DIPLOMÁTICA EN EL ÁMBITO DE LAS RELACIONES INTERNACIONALES CONTEMPORÁNEAS
}

\author{
Manuel Morales Lama ${ }^{1}$
}

\section{RESUMO}

O presente artigo enfoca a atual conjuntura internacional das relações internacionais entre os Estados, com sua dinâmica natural no novo milênio. $O$ sistema vigente de relações diplomáticas apresenta uma roupagem nova, em que os seus representantes, amparados pelo Direito Internacional, resguardam os interesses nacionais de seus países, mas se apresentam como representantes plenipotenciários nas áreas econômicas, política, social, científica, tecnológica e cultural.

Palavras-chave: Relações Internacionais; Assistência Consular; Política Exterior; Direito Internacional;

\begin{abstract}
The aim of this article is to analyze the context of international relations among the States, imbued of a natural dynamics of this New Millennium. The present system of diplomatic relations presents a new momentum in which its representatives, under the International Law, focus their actions on the interests of their countries, but are very active in the economic, political, scientifically, technological and cultural areas.
\end{abstract}

Key-words: international relations, consular assistance, foreign trade, international law.

\section{Introducción}

En la actual coyuntura internacional, las relaciones entre los Estados están experimentando cambios fundamentales e indispensables para poder enfrentar adecuadamente los retos del nuevo milenio.

El sistema vigente de relaciones diplomáticas cuenta con una nueva dinámica que ha logrado adecuar funciones básicas tradicionales a los requerimientos contemporáneos, sustentándolos en el derecho internacional moderno. Como es sabido, una de las funciones más relevantes de la Misión Diplomática es la protección de los intereses del Estado que ésta representa y de sus nacionales (residentes temporales o permanentes en el Estado receptor). A pesar de que el mundo se encuentra en el inicio de un ciclo histórico caracterizado por cambios extraordinarios en casi todos los órdenes, dicha función ha continuado desempeñándose sin choque alguno con el proceso de transformación que está llevándose a cabo en el sistema internacional, al menos en las etapas actuales.

La protección de los nacionales de un Estado, residentes en el exterior, fue originalmente una función que correspondió casi exclusivamente a la institución consular. No obstante, de acuerdo a los preceptos de la Convención de Viena sobre

\footnotetext{
${ }^{1}$ Manuel Morales Lama é jurista e Embaixador da República Dominicana no Brasil.
} 
Relaciones Diplomáticas de 1961, ésta es también una de las obligaciones básicas de la Misión Diplomática. La cual, como otras funciones del ejercicio diplomático (y consular), tiene el deber de realizarse dentro de los límites permitidos por el derecho internacional.

En cambio, a través de la historia, la Misión Diplomática se ha ocupado más ampliamente de la protección de los intereses del Estado que representa. Esta responsabilidad la ejecuta la Misión paralelamente a las funciones de observación e información con las que guarda estrechos vínculos. Por medio de ellas, el Jefe de la Misión Diplomática mantiene enterado a su gobierno (a través de su Cancillería), entre otros importantes aspectos, sobre la verdadera realidad económica, política, social, científica, tecnológica y cultural del país en que ejerce sus funciones. Esta responsabilidad incluye la veraz información sobre los sucesos más importantes ocurridos en el Estado receptor, particularmente en los órdenes comercial, administrativo, económico, financiero y político, así como sobre reformas de carácter legislativo.

Las precedentes ejecutorias están encaminadas, en el ámbito de la globalización, a salvaguardar los intereses preestablecidos de la política exterior de cada Estado, dentro de la dinámica de la política internacional, y requieren de una Cancillería receptora capaz de clasificar, evaluar, analizar y, si fuera necesario, depurar toda la documentación recibida del exterior para enriquecer el banco de datos que permita al Poder Ejecutivo la formulación con la debida precisión y seguimiento de las acciones de la política exterior del Estado.

Conviene recordar que la función de protección, tradicionalmente, ha sido entendida como el conjunto de acciones que un Estado ejerce frente a otro Estado, por medio de sus representantes diplomáticos o consulares, para resguardar a sus nacionales que no sean reconocidos como tales por el segundo Estado y que residan de manera temporal o permanente en el territorio extranjero. De lo que puede colegirse que esta función se limitaba sólo al amparo diplomático y consular que se concedía entonces (y que se continúa concediendo) a los nacionales de un Estado. A lo que puede añadirse que este amparo se sustenta en el principio de igualdad de derechos de nacionales y extranjeros.

De igual manera, el amparo se fundamenta en la obligación impuesta por el derecho internacional a los Estados, de asegurar a los extranjeros que se hallan en su territorio "un trato no inferior a cierto grado mínimo". Asimismo, puede originarse en acuerdos bilaterales denominados "tratados de establecimiento" que preveen con precisión los derechos y deberes de los ciudadanos extranjeros.

En la práctica internacional se establece la diferencia entre el amparo diplomático y el amparo consular. El primero de ellos es ejecutado por agentes diplomáticos a solicitud de un nacional del país al que representan, luego de que éste haya agotado los recursos internos, sobre todo en los casos de una comprobada denegación de justicia. Este tipo de protección se inicia con el envío de una nota diplomática a la Cancillería del Estado receptor, previo a lo cual, el Jefe de Misión en cuestión habrá informado debidamente a su Cancillería sobre el caso, y si lo estima necesario puede solicitar la correspondiente autorización de ésta antes de iniciar el procedimiento. La responsabilidad internacional admite la reclamación diplomática en los casos de denegación de justicia, también cuando hay retardo injustificado de su administración, o bien en casos de sentencia en contra del Derecho. 
Al ejercer esta función, el Jefe de Misión Diplomática debe tener siempre presente: "Que sobre el interés del ciudadano debe prevalecer el del Estado, que es expresión del interés colectivo" (D. Antokoletz). ${ }^{2}$

\section{El Amparo Consular}

En cambio, el amparo consular es una acción que corresponde a los funcionarios consulares y que es ejercida ante autoridades locales (o de otro tipo) dentro de la circunscripción que les corresponde, siendo, por lo general, el beneficiario una persona indefensa frente a faltas o violaciones en la aplicación del derecho interno y "aún en instancias en las cuales no se han agotado los recursos legales internos".

Coexiste con la protección (o amparo) la denominada asistencia consular, consistente en las ejecutorias que el Jefe de la oficina consular realiza a favor de los nacionales del Estado que representa, sin que intervenga la autoridad extranjera. Esta asistencia se fundamenta en: A. El reconocimiento del Estado receptor, de acuerdo al derecho convencional, de la autoridad del funcionario consular para ejercer dichas acciones. B. La debida responsabilidad del Estado de origen para atender el bienestar de sus nacionales, aun fuera de los límites territoriales.

La asistencia consular, si bien no implica una reclamación derivada de una falta a los derechos de los nacionales o una deficiencia en los procesos judiciales, sí constituye el grueso de las actividades consulares, y de ella derivan, en muchas instancias, las labores de protección propiamente dichas.

Cabe señalar que la protección no procede cuando tenga como propósito pretender para el nacional un trato privilegiado en comparación con los nacionales del Estado receptor, "salvo que se trate de derechos elementales estipulados por el derecho internacional, como los relacionados con la esclavitud y la prostitución".

Conviene puntualizar que un Estado no puede pretender proteger a sus nacionales contra la aplicación del derecho interno de otro, si esta aplicación se realiza en igualdad de circunstancias para todos los habitantes de ese país. Como es sabido, fueron los "excesos" en las reclamaciones en el ámbito de la protección los que motivaron la Doctrina Calvo, la cual sostiene en esencia "que un extranjero que radica en otro país se beneficia con la emigración, y no debe pretender, por tanto, tener derecho a un régimen diferente y más favorable que el de los nacionales del país".

Con relación al amparo diplomático, el Sistema Interamericano fijó su posición al respecto en el Pacto de Bogotá de 1948 (Art. VII), donde expresa: "Las altas partes contratantes se obligan a no intentar reclamación diplomática para proteger a sus nacionales ni a iniciar al efecto una controversia ante la jurisdicción internacional cuando dichos nacionales hayan tenido expeditos los medios para acudir a los tribunales domésticos competentes del Estado respectivo". 3

Es oportuno recordar que para que un Estado pueda proporcionar protección se requiere A. Que el afectado sea nacional del Estado del que solicite su protección. B. Que el interesado solicite la protección, y C. Que la relación sea planteada en tiempo y forma.

La protección o amparo, tanto diplomático como consular, se presenta desde el punto de vista jurídico como un reclamo a "la responsabilidad internacional de los Estados", en aquellos casos en que los ciudadanos del país reclamante, en sus personas, sus bienes o sus intereses hayan sido agraviados. La responsabilidad internacional nace

$\left(^{2}\right)$ D. Antokoletz, Tratado Teórico y Práctico de Derecho Diplomático y Consular (Buenos Aires: Editora Ideas, 1948) pág. 31.

$\left(^{3}\right)$ Citado por C. Sepúlveda, Derecho Internacional (México: Editorial Porrúa, 1988), pág. 240. 
de la realización de un hecho "ilícito internacional" que se traduce en la omisión o "la violación" de dichas normas, por un Estado, en contra de las personas, los bienes o derechos de otro Estado.

Existen dos tipos de violaciones internacionales, las que implican la comisión de un crimen, y otras que se denominan como delitos.

Los crímenes constituyen una violación grave para el mantenimiento de la paz y la seguridad internacional, "como la transgresión de los postulados de no-agresión, la práctica de la esclavitud, del genocidio, o un daño mayúsculo al medio ambiente".

Los delitos son ofensas de gravedad menor, por las cuales el Estado lesionado jurídicamente está autorizado a reclamar la responsabilidad del Estado agresor, sólo si las violaciones pueden ser denunciadas por sujetos internacionales distintos del Estado denunciante lesionado.

Es importante señalar que el comportamiento de cualquiera de los poderes del Estado (Ejecutivo, Legislativo, Judicial u otro órgano dentro del marco de la organización estatal) se considera como atribuible al Estado. También las conductas emanadas de una entidad que no forma parte de la estructura misma del Estado o de una entidad pública territorial, pero que el derecho interno faculta para ejercer prerrogativas del poder público.

La práctica internacional ha establecido de modo concluyente la responsabilidad internacional de los actos no autorizados de sus órganos aun cuando éstos se realicen fuera de los límites de su competencia y sean contrarios al derecho interno.

De otro lado, el Estado no será responsable de los actos u omisiones en que incurran los funcionarios que posean status de órganos cuando actúan privadamente. De igual forma, el Estado no asume responsabilidad sobre el comportamiento de los integrantes de un movimiento de insurrección, a menos que éstos lleguen a convertirse en el nuevo gobierno.

Por último, se imputa al Estado el comportamiento de un órgano o varios órganos puestos a su disposición por otro Estado o por una organización internacional, siempre y cuando dichos órganos actúen sobre la base de prerrogativas del poder público del mismo.

Se consideran circunstancias excluyentes de la responsabilidad internacional de Estado, el consentimiento, la fuerza mayor (y el caso fortuito), el peligro extremo, el estado de necesidad, las contramedidas y la legítima defensa:

-El consentimiento, entendido como un acuerdo entre los Estados, para dejar sin efecto la obligación en cuestión. Para llegar a éste se requiere que el mismo sea válido, que conste claramente, que sea anterior a la comisión u omisión del hecho al que se refiera y que no se derive de normas del ius cogens.

-La fuerza mayor y el caso fortuito, que se refiere a una fuerza irresistible o acontecimiento de naturaleza imprevista y que haga imposible la actuación del Estado de acuerdo con sus obligaciones internacionales, y que el mismo no haya contribuido intencionalmente o negligentemente a la aparición de esa circunstancia.

-El peligro extremo, el cual se aplica como circunstancia excluyente cuando encuentra en peligro la vida del individuo u órgano del Estado, o del conjunto de personas que se encuentran a su cuidado. Esto siempre y cuando el Estado no haya propiciado dicha situación.

-El Estado de necesidad se puede invocar cuando la realización de un hecho haya sido el único medio para salvaguardar un interés esencial del Estado frente a un peligro inminente, que ese hecho no haya afectado gravemente al Estado para con el cual existía la obligación. No se puede aducir peligro inminente cuando la obligación emana de una 
norma del ius cogens", o si esta posibilidad existe por un Tratado o si el Estado ha contribuido a la aparición de este estado de necesidad.

-Las contra-medidas, como sanciones que el derecho internacional permite sean ejercidas por un Estado afectado por el incumplimiento de una obligación internacional, pueden ser consideradas como excluyentes de responsabilidad del Estado, si estas medidas guardan proporción con la violación cometida.

- La legítima defensa, si ésta constituye una medida lícita ejecutada de acuerdo con los postulados de la Carta de la Organización de las Naciones Unidas, Artículo 51. Los requisitos son: que exista un ataque armado de un tercer Estado, que se comuniquen esas medidas al Consejo de Seguridad de las Naciones Unidas, en el entendido, de que las mismas no limitan de manera alguna la autoridad y responsabilidad del mismo Consejo para mantener la paz y la seguridad internacionales.

Existen actos que no son sancionados por el derecho internacional y que a pesar de su naturaleza lícita, son altamente peligrosos, por lo que para algunos estudiosos del tema, deberían ser regulados con el fin de sustentar la responsabilidad internacional de sus ejecutores.

Como ejemplo de lo anterior, tenemos el caso de la utilización pacífica de la energía nuclear y los daños causados por satélites en la superficie terrestre, entre otros. En este sentido, se habla ya de diversos conceptos como "actividades peligrosas", "riesgo excepcional" y "daño considerable", pero no se ha llegado a delimitar la responsabilidad de los entes con personalidad jurídica internacional, en especial la de los Estados.

El derecho internacional admite tres formas de reparación en estos casos, que son: la restitución, la indemnización y, por último, la satisfacción.

La primera busca restituir la situación al estado previo de circunstancias que prevalecía antes de que se causara el daño. La indemnización compensa en monetario a las víctimas del agravio y constituye la forma más común de reparación, y por último, la satisfacción, que se puede traducir en la disculpa de los funcionarios responsables o en la sanción o aplicación rigurosa de la legislación interna como castigo al agresor.

La teoría de la responsabilidad de los Estados en el orden jurídico internacional es relativamente reciente. En el siglo 19 la noción de la soberanía absoluta del Estado no dejaba campo para concebirlo como responsable ante otro Estado. Fue necesario el surgimiento de la moderna tesis del "Estado de Derecho" para que se encontrara cabida al tema de la responsabilidad internacional. (C. Sepúlveda).

\section{Notas Finales}

En la actualidad la importancia que se otorga a las funciones de protección no se limita a las responsabilidades del servicio exterior. Hoy existen modernas Cancillerías que cuentan con Direcciones Generales que se encargan exclusivamente de esta función, a la que se adscriben unidades especializadas para cada una de las responsabilidades, como son: de Buenos Oficios (para sucesiones, indemnizaciones, tutela o curatela de menores incapacitados, localizaciones, etc.), de Asuntos Legales (para asuntos civiles y penales, extradición, repatriación, etc.), de Asuntos Laborales, de Estudios sobre Nacionales (del país) en el Extranjero, de Recuperación de Valores, de Seguimiento de Casos y Apoyo Administrativo, entre otras.

Por último, conviene señalar que la protección reviste otros múltiples y variados aspectos, como es la protección que debe otorgar el Cónsul a la Marina y Aviación

( ${ }^{4}$ ) C. Sepúlveda, op. cit., 235. 
Nacionales o bien los deberes del servicio exterior de proteger aspectos generales de su país, entre los que se encuentran el acervo histórico y cultural de la nación, las instituciones nacionales, la imagen y prestigio de su país y el ámbito de la ley nacional en lo que no se oponga a la del Estado receptor.

Conviene recordar que la pujante corriente globalizadora está imponiendo nuevos retos al interés de cada Estado. La aparición de canales de comunicación entre gobiernos se reconoce como parte esencial de la estrategia de protección, ya que aminora la incidencia de casos y hace más expedita la resolución de reclamos.

Si el Acuerdo Multilateral de Inversión es firmado y ratificado, tal y como se espera en un futuro cercano, la protección diplomática de los intereses generados por el capital, se planteará no sólo frente al Estado sino a través de una organización internacional, la cual tendrá facultades para crear una instancia supranacional. Esto, de acuerdo a M. E. Rosas, representará una novedosa variante que puede abrir otras muchas pautas en el futuro.

Sin embargo, también plantea conflictos jurídicos irresolubles ante el concepto tradicional de soberanía y el principio de la no intervención en los asuntos internos de otros Estados. Las nuevas tendencias parecen querer replantear la actuación soberana de los Estados frente a los derechos de los individuos. Será interesante observar el desempeño del ejercicio de la función de protección en estos nuevos ámbitos e instancias para determinar si en realidad pueden resolver con mayor eficiencia los reclamos en materia de protección, o bien si éstas llegan a cambiar sustancialmente la naturaleza de tan delicada función.

Finalmente, cabe resaltar que la complejidad e importancia del ejercicio diplomático y consular contemporáneos, en general y particularmente para la función de protección, requieren un servicio exterior con la capacidad, experiencia y vocación de servicio a la altura de las necesidades y aspiraciones del país que representa.

\section{Bibliografía}

- Aguilar Benítez de Lugo, Mariano. Lecciones de Derecho Civil Internacional (Madrid: Técnos, 1996).

- Amaral Júnior, Alberto do. O Direito de Assistência Humanitária (Rio de Janeiro: Renovar, 2003).

- Barston, R.P., Modern Diplomacy (New York: Longmans, 1998).

- Borzi Alba, María Angélica T. Inmunidades y Privilegios de los Funcionarios Diplomáticos (Buenos Aires: Abeledo-Perrot, 1982).

- Burton, J.W., Teoría General de las Relaciones Internacionales (México: UNAM, 1986).

- Cançado Trindade, Antônio Augusto. A Nova Dimensão do Direito Internacional (Brasília: Instituto Rio Branco, 2003).

- Cançado Trinidade, Antônio Augusto. A Humanização do Direito Internacional. (Belo Horizonte: Del Rey, 2006).

- Cancillo, José María. La Profesionalidad del Diplomático (Buenos Aires, Emece Ed., 1993). 
- Canêdo Gonçalves da Silva, Carlos A.. Direito Internacional Moderno (Belo Horizonte: Mandamentos Editora, 2004).

- Cavarzere, Thelma Thais. Direito Internacional da Pessoa Humana (Rio de Janeiro: Renovar, 2001).

- Colegio de Abogados de México. "El Pensamiento Jurídico de México en el Derecho Internacional” (México: Ed. Porrúa, 1960).

- de Olloqui, José Juan. La Diplomacia Total (México: FCE, 1994).

- Depetre, José Lion. Derecho Diplomático (México: Textos Universitarios, 1974).

- Figueroa Cedeño, Edna. Concordancias Consulares (Caracas, Ministerio de Relaciones Exteriores, 1997).

- González Tapia, José. Legislación Migratoria Dominicana (Santo Domingo: 1984).

- Jara Roncati, Eduardo. La Función Diplomática (Santiago: PNUD/CEPAL, 1982).

- Lima Marques, Claudia. O Novo Direito Internacional (Rio de Janeiro: Renovar, 2005).

- Mcclanahan, GRANT V. Diplomatic Immunity: Principles, Practices and Problems (Washington: Georgetown University, 1989).

- Milán Lugo, Gloria. Manual Consular (Santo Domingo, Centro Editorial, 1995).

- Morales Lama, Manuel. "De la Institución Consular a la Función Diplomática Comercial”. Listín Diario (Santo Domingo, 17 de enero de 1997). P. 9A.

- Morales Lama, Manuel. "El Servicio Exterior y los Nacionales en el Extranjero". Listín Diario, Edición Digital (Santo Domingo, 1 de abril de 2005).

- Morales Lama, Manuel. "Protección y Asistencia a los Nacionales en el Exterior". Listín Diario (Santo Domingo, 16 de junio de 2002). P. 17A.

- Morales Lama, Manuel. "Proyectos de Vinculación para los Profesionales en el Exterior". Listín Diario (Santo Domingo, 19 de mayo de 2006). P. 11A. 
- Morales Lama, Manuel. Diplomacia Contemporánea: Teoría y práctica, para el Ejercicio Profesional (Santo Domingo: Fundación Antonio M. Lama, Sexta Edición, 2004).

- Moreno Pino, Ismael. La Diplomacia: Aspectos Teóricos y Prácticos (México: SRE, 1996).

- Ochoa Brun, Miguel A., Historia de la Diplomacia Española (Madrid: Ministerio de Asuntos Exteriores, 1990). 1948).

- Oppenheim-Lauter, P., International Law (Londres: Grend and Co.,

- Passantes García, Armando. Las Relaciones Internacionales (Quito: CYMA, 1969).

- Pastor Ridruejo, José A. Curso de Derecho Internacional Público y Organizaciones Internacionales (Madrid, Técnos, 1996).

- Pérez de Cuellar, Javier. Manual de Derecho Diplomático (México: Fondo de Cultura Económica, 1997).

- Pérez Otermin, Jorge. Política Exterior y Profesionalismo (Montevideo: OEA, 1992).

- Quel López, F. Javier. Los Privilegios e Inmunidades de los Agentes Diplomáticos en el Derecho Internacional (Madrid: Editora Civitas S.A., 1993).

- Ramacciotti, Beatriz. Derecho Internacional Público (Lima: Pontificia Universidad Católica del Perú, 1993).

- Reis, Henrique Marcello dos. Relações Econômicas Internacionais e Direitos Humanos (São Paulo: Editora Quartier Latin do Brasil, 2005).

- Sánchez Rúbio, David. Direitos Humanos e Globalização (Rio de Janeiro: Editora Lumen Juris, 2004).

- Sánchez y Sánchez, Carlos. Curso de Derecho Internacional Público (Santo Domingo, Editora Montalvo, 1943).

- Secretaría de Relaciones Exteriores de México. "Ley Orgánica del Servicio Exterior Mexicano”, 1996.

- Seitenfus, Ricardo. Direito das Relações Internacionais (Porto Alegre: Livraria do Advogado Editora, 2002). 1988).

- Sepúlveda, César. Derecho Internacional (México: Editora Porrúa, 
- Verdross, Alfred. Derecho Internacional Público (Madrid: Biblioteca Jurídica Aguilar, 1976).

- Vicioso Soto, Horacio. Diplomacia, Ciencia y Arte (Santo Domingo: Efa Impreso, 1993).

- Woodford, Protese y Schimitt, Conrad J., Ciencia Política y Relaciones Internacionales (New York: MoGraw-Hill, Inc. 1993).

- Xilotl Ramírez, Ramón. Derecho Consular Mexicano (México: Ed. Porrúa, 1982).

- Xilotl Ramírez, Ramón. Ensayos Jurídicos-Consulares (México: SRE, 1987).

- Zorbibe, Charles. Les Relations Internacionales (París: PUF, 1975). 